domains: Two Z-alpha domains, three dsRNA-binding domains and the putative deaminase domain, which are located in exon 2, exons 2-7 and exons 9-14 respectively [4]. The deaminase domain of the DSRAD protein is located in the codon from 886 to 1,221 , which is approximately $30 \%$ of the full length of the DSRAD protein. These results suggest that the deaminase domain might be a hot spot for mutations [5]. The missense mutation c. $3073 \mathrm{~A}>\mathrm{G}$ alters a conserved amino acid residue at 958 in exon 10, which is located in the putative deaminase domain, so the amino acid residue at 958 is suspected to play an important role in the conformation of the catalytic site of the enzyme, and the mutation at this position could probably compromises enzyme activity [6].

In conclusion, the results provide an addition to the DSH mutation database and will contribute further to the understanding of DSH genotype/phenotype correlations and to the pathogenesis of this disease. In a future study, we will construct the p.H958R mutant of DSRAD, and explore the pathogenesis of DSH.

Acknowledgements. This work was supported by the National Natural Science Foundation of China (No.30371295). Conflict of interest: none.

Department of Dermatology, Second

Hospital of Xi'an Jiaotong

University, $157 \mathrm{Xi}$ Wu Road, Xi'an,

Shaanxi, 710004, China

${ }^{1}$ These authors all contributed

equally to this work.

<Xiao_SX@163.com>

1. Zhang X, Gao M, Li $M$, et al. Identification of a locus for dyschromatosis symmetrica hereditaria at chromosome 1q11-1q2. J Invest Dermatol 2003; 120: 776-80.

2. He PP, He CD, Cui $Y$, et al. Refined localization of dyschromatosis symmetrica hereditaria gene to a 9E-4-cM region at lq21-22 and a literature review of 136 cases reported in China. Br J Dermatol 2004; 150: 633-9.

3. Ren JW, Luo SJ, Peng ZH, Liu Y, Pan M, Xiao SX. Novel frameshift mutation of the DSRAD gene in a Chinese family with dyschromatosis symmetrica hereditaria. J Eur Acad Dermatol Venereol 2008; 22: $1375-6$.

4. Wang $Y$, Zeng $Y$, Murray JM, Nishikura K. Genomic organization and chromosomal location of the human dsRNA adenosine deaminase gene: the enzyme for glutamate-activated ion channel RNA editing. $J$ Mol Biol 1995; 254: 184-95

5. Suzuki N, Suzuki T, Inagaki K, et al. Ten novel mutations of the ADAR 1 gene in Japanese patients with dyschromatosis symmetrica hereditaria. J Invest Dermatol 2006; 127: 309-11

6. Miyamura $Y$, Suzuki T, Kono M et al. Mutations of the RNAspecific adenosine deaminase gene (DSRAD) are involved in dyschromatosis symmetrica hereditaria. Am J Hum Genet 2003; 73: 693-9.

doi: 10.1684/ejd.2009.0639

\section{Hansen's disease in an HIV patient complicated by deep vein thrombosis: a rare complication of thalidomide therapy}

A 33-year-old man $\mathrm{HIV}_{1}$-positive (born in Angola and a resident of Portugal since 1997), treated with high antiretroviral treatment (HAART) since 1999, was diagnosed with borderline leprosy, in a type 2 reaction, and was treated with multibacillary-multidrug therapy, as defined by the WHO, in combination with prednisolone $(60 \mathrm{mg} /$ day). Three months later, thalidomide therapy $(200 \mathrm{mg} /$ day) was successfully introduced to control severe and recurrent Erythema Nodosum Leprosum (ENL). Six weeks later, the patient developed dyspnea and severe edema in both legs (figure 1).

Homan's sign was positive and a doppler ultrasonography revealed massive adherent thrombosis in both popliteal and femoral veins, extending to the common iliac vein. Angio-CT was consistent with pulmonary thromboembolism with pulmonary infarction. A potential prothrombotic state was excluded following analysis of erythrocyte and platelet counts, lipidemia, proteins $\mathrm{C}$ and $\mathrm{S}$ blood levels, search for resistance to activated protein $\mathrm{C}$ and antithrombin III levels, lupus anticoagulant, anticardiolipin or anti- $\beta_{2}$-glycoprotein antibodies. Moreover, the patient did not have any other associated thrombotic risk factors, including cigarette smoking, infrequent or heavy hard drug use, immobility, malignancy, heart disease, inflammatory bowel disease, nor a history of previous thrombotic episodes.

Thalidomide therapy was discontinued and the patient was treated with subcutaneous low-molecular weight heparin (enoxaparin $80 \mathrm{mg}$ b.i.d.) and oral warfarin. His condition progressively improved and, after successful anticoagulation therapy, thalidomide was safely restarted and a vena cava filter implanted. One year later the patient remains well, medicated with MB-MDT, thalidomide $200 \mathrm{mg} /$ day, warfarin and prednisolone $(10 \mathrm{mg} /$ day).

The first reports of thrombotic complications related to thalidomide therapy were observed in a series of 5 patients, 4 with lupus erythematous and 1 with severe atopic dermatitis (all with thrombotic risk factors) [1]. In addition, thalidomide-triggered thrombosis had been reported in patients with cicatritial pemphigoid, sarcoidosis or aphthosis and during the treatment of malignancy (multiple myeloma and renal-cell carcinoma), particularly when associated with chemotherapy [2-5]. Almost 6500 ENL patients who did not respond to other treatment drugs have been treated with thalidomide. Among them, DVT was reported in only two patients but neither had

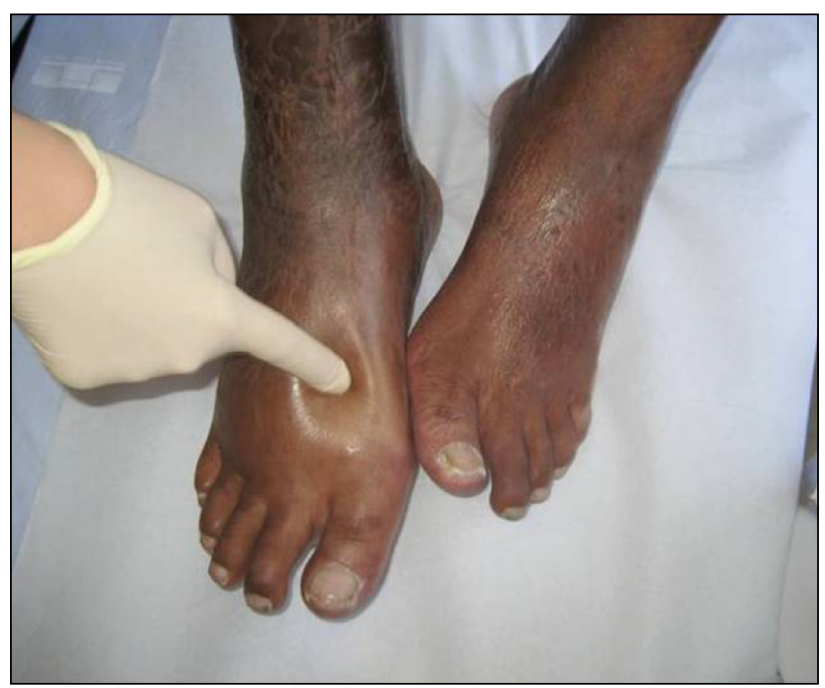

Figure 1. Edema of both legs, more accentuated in the right foot with a positive Godet sign. 
associated pulmonary thrombosis. The first patient received concomitant dexamethasone-cyclophosphamide pulses [4] and the second was similarly treated with prednisolone [5]. In those cases DVT developed after eight and six weeks post thalidomide therapy, respectively, but in neither case was thalidomide restarted. Interestingly, in our patient this drug was safely restarted two weeks later following successful anticoagulation therapy and one year later the patient is still being treated (with concomitant corticosteroids) without further complications. In retrospect, we recognize that it was possible in our patient that corticotherapy and HIV infection contributed to thrombosis development. In fact, Vetrichevel et al. recently suggested that there was a possibility of thrombosis in patients receiving thalidomide therapy together with corticosteroids i.e., both drugs have a synergistic, suppressive effect on thrombomodulin because they inhibit/ decrease the production of TNF- $\alpha$ [5]. Currently available epidemiological evidence also suggests that chronic HIV infection is associated with a two- to ten-fold increased risk of venous thrombosis in comparison to an agematched control population [6]. The hypercoagulable state present in many HIV patients is associated with an increased risk of haemostatic changes and of superimposed infections. HAART has also been associated with an amplified risk of DVT by some investigators, however, the data are insufficient to support these claims [6].

This case highlights the increased thrombosis risk following thalidomide therapy in an HIV/leprosy co-infected patient without major thrombotic risk factors, even when used as an indicated treatment for ENL, and highlights the possible danger of not diagnosing DVT in an ENL patient since edema of both legs is a common occurrence during this reaction.

Acknowledgements. Conflict of Interest Disclosure: None declared. Funding sources: none.

${ }^{1}$ Dermatology Department, Curry
Cabral Hospital, Rua da
Beneficiencia n ${ }^{\circ} 8,1069-$
166 Lisbon, Portugal
${ }^{2}$ Internal Medicine Department,
Curry Cabral Hospital
${ }^{3}$ Dermatopathologie,
Friedrichshafen, Germany
${ }^{4}$ Pathology Department, Curry
Cabral Hospital
${ }^{5}$ Infectious Disease Department,
Curry Cabral Hospital
$<$ sandradmedeiros@clix.pt>

Sandra MEDEIROS $^{1}$
Candida FERNANDES
Nídia MARTINS $^{2}$
João MACHADO $^{2}$
Heinz KUTZNER $^{3}$
Ana AFONSO $^{4}$
Raquel VIEIRA $^{1}$
Fernando MALTEZ $^{5}$
Jorge CARDOSO $^{1}$

1. Flageul B, Wallach D, Cavelier-Balloy B, Bachelez H, Carsuzaa F, Dubertret L. Thalidomide and thrombosis. Ann Dermatol Venereol 2000; 127: 171-4.

2. Howell $E$, Johnson $S$. Venous thrombosis occurring after initiation of thalidomide for the treatment of cicatricial pemphigoid. J Drugs Dermatol 2004; 3: 83-5.

3. Zangari M, Anaissie E, Barlogie B, Badros A, Desikan R, Gopal AV, Morris C, Toor A, Siegel E, Fink L, Tricot G. Increased risk of deep-vein thrombosis in patients with multiple myeloma receiving thalidomide and chemotherapy. Blood 2001; 98: 1614-5.

4. Sharma NL, Sharma V, Shanker V, Mahajan VK, Sarin S. Deep vein thrombosis: a rare complication of thalidomide therapy in recurrent erythema nodosum leprosum. Int J Lepr Other Mycobact Dis 2004; 72: 483-5

5. Vetrichevvel TP, Pise GA, Thappa DM. A case report of venous thrombosis in a leprosy patient treated with corticosteroid and thalidomide. Lepr Rev 2008; 79: 193-5.
6. Klein SK, Slim EJ, de Kruif MD, Keller TT, ten Cate H, van Gorp EC, Brandjes DP. Is chronic HIV infection associated with venous thrombotic disease? A systematic review. Neth JMed 2005; 63: 129-36.

doi:10.1684/ejd.2009.0641

\section{Tocilizumab-induced erythroderma}

Tocilizumab is a humanized anti-human interleukin 6 receptor (IL-6R) antibody, engineered by grafting the complementarily determining regions of a mouse antihuman IL-6R antibody into human IgG1 to create a human antibody with a human IL-6R binding site [1,2]. Tocilizumab binds to the IL-6 binding site of human IL6R and competitively inhibits IL-6 signaling. A series of clinical studies have shown that inhibition of IL-6 signaling by tocilizumab is therapeutically effective in Castleman disease and rheumatoid arthritis (RA). In Japan, tocilizumab began to be widely used for patients with Castleman disease and RA refractory to other therapies in 2005 and 2008, respectively. We report a 62-year-old Japanese woman who developed erythroderma after administration of tocilizumab for her RA.

Twenty four years before our first examination, the patient was diagnosed as having RA because of multiple arthralgia. Although she took oral non-steroidal antiinflammatory drugs (NSAID), oral corticosteroid and methotrexate, the arthralgia gradually worsened. She was referred to our hospital for further treatment of RA. The patient began to receive an intravenous injection of tocilizumab, $280 \mathrm{mg}(8 \mathrm{mg} / \mathrm{kg})$ once per month. Two days after the first injection, the patient noticed a slight erythematous eruption on her face, which subsided in a few days. One day after the second injection, she again developed erythema on the face to chest, although, it disappeared in a few days without any treatment. A few hours after the third injection of tocilizumab, generalized erythema developed on the whole body with severe itch (figure 1). There was no oral exanthema. A peripheral blood sample showed a normal leukocyte count of 4800/ $\mu \mathrm{L}$ (Normal: 3500-9500) with $15.9 \%$ eosinophils (763/ $\mu \mathrm{L})$. The serum levels of hepatic enzymes were within normal ranges. She had neither a high fever nor lymph node swelling, suggesting that she did not suffer from viral infection. We could not obtain her informed consent for a skin biopsy. Since the eruption and eosinophilia occurred in accordance with the drug injection, we diagnosed her erythroderma as a skin eruption due to tocilizumab. Since we could not obtain her informed consent for further examinations, we did not perform skin patch testing or lymphocyte stimulation tests. The administration of tocilizumab was discontinued and the erythroderma subsided in a week with topical betamethasone butyrate propionate alone.

Tocilizumab inhibits the signaling of IL-6, an important inflammation moderator. Several kinds of serious adverse events due to tocilizumab have been reviewed by Nishimoto $\mathrm{N}$ et al. [3]. Infections such as pneumonia, herpes zoster, acute bronchitis and pyelonephritis are the most frequently observed side effects. However, aside from herpes zoster, only one case of cutaneous adverse effects of tocilizumab has been reported in the English literature [4]. 